\title{
Surface Morphology and Bending Deformation of 2024-T3 Thin Sheets with Laser Peen Forming
}

\author{
Junfeng $\mathrm{Wu}^{1, \mathrm{a}}$, Shikun Zou ${ }^{1}$, Yongkang Zhang ${ }^{2}$ and Shuili Gong ${ }^{1}$ \\ ${ }^{1}$ Science and Technology on Power Beam Processes Laboratory, AVIC Manufacturing Technology Institute, Beijing \\ 100024, China \\ ${ }^{2}$ School of Electro-mechanical Engineering, Guangdong University of Technology, Guangzhou, Guangdong, \\ 510000, PR China
}

\begin{abstract}
Laser peen forming (LPF) is a pure mechanical forming method through accumulated plastic strain, which has been successfully applied in wing components. Experimental investigation has been performed to understand the effect of process parameters such as constraint conditions, sheet thickness and laser energy on surface morphology and bending deformation of 2024-T3 thin sheets of dimensions of $76 \mathrm{~mm} \times 19 \mathrm{~mm}$ (length $\times$ width). The research results indicated that bulges on the aluminum foil were generated at the bottom surface and not generated at the topmost surface. It was different for transition value of twoway bending deformations of thin sheets after LPF with different constraint conditions. Remain flat thicknesses of thin sheets after LPF were about $1 \mathrm{~mm} \sim 2 \mathrm{~mm}$ for $20 \mathrm{~J}, 25 \mathrm{~J}$ and $30 \mathrm{~J}$. Arc heights and curvatures of $3 \mathrm{~mm}$ thickness sheets increased with laser energy and those of $2 \mathrm{~mm}$ thickness sheets only made little change. It was found that convex deformation, flat, concave deformation and laser deep drawing for thin sheets with different thicknesses after LPF.
\end{abstract}

\section{Introduction}

Laser peen forming (LPF), derivative laser shock processing (LSP), has been developed as a metal forming method for flexible shaping and adjusting. Because of some advantages such as non-contact, tool-free and high efficiency, LPF has been successfully applied for forming of B747-8 wing panel [1]. In addition, compressive residual stresses after LPF are generated both on two sides of plates, which would contribute to resist the stress corrosion crack and fatigue [2, 3].

Bend deformation of thin sheets with LPF has attracted much concern in the past several years because of demands of micro-electromechanical system (MEMS) fabrication and bending deformation mechanism. Hu et al. [4] addressed effect of process parameters on the bending deformation of aluminum alloy thin sheets with different thicknesses at cantilever state and proposed the forming mechanism about two-way bending deformations. Ocana et al. [5] presented the influence of process parameters on the net bending angle of thin sheet metals. Sagisaka et al. [6, 7] showed the changes of bending property with atmosphere, process parameters and elastic pre-bending on pure aluminum thin sheets. $\mathrm{Hu}$ et al. [8, 9] discussed the bending capability of thin sheet metals, residual stress distributions and the microstructure close to their opposite sides. Shen et al. [10] analyzed the surface modification of aluminum alloy thin sheets. However, surface morphology and bending deformation

\footnotetext{
a Junfeng Wu:wjf88813@163.com
} 
of different thin sheets thicknesses are still little studied under different constraint conditions and different laser energies. Researched results would contribute to fundamental process experiment for large-scale thin sheets with LPF, which can be beneficial to the application of LPF in the contour design of aircraft wing skin panels.

This paper aims to study the surface morphology and bending deformation of 2024-T3 thin sheets with different thicknesses after LPF under different process conditions. Then surface morphology of aluminum alloy both at the topmost surface and at the bottom surface was analyzed. Arc heights and bending profiles of thin sheets were discussed. Furthermore, different bending deformation types were analyzed.

\section{LPF experiment and measured methods}

LPF, a derivative of LSP, is a new mechanical process to make the target bend deformation without heat effect, as shown in Fig. 1. Under high compressive shock loading, plastically deformated layer with high strain rates (up to $10^{6} \mathrm{~s}^{-1}$ ) is generated in the surface layer. In order to balance plastic strain and plastic stress induced by LPF, the target bends and stretches. The convex or concave deformations depend on the plastically deformed layer depth at the cross-section $[4,11]$.

2024-T3 aluminum alloy thin sheets with different thicknesses were used to study the surface morphology and bending deformation after LPF. The dimensions of thin sheets were $76 \mathrm{~mm} \times 19 \mathrm{~mm}$ (Length $\times$ width). The thicknesses are $3 \mathrm{~mm}, 2 \mathrm{~mm}$ and $1 \mathrm{~mm}$, respectively. Thin sheets were wirely cut from one piece of plate and the length direction of thin sheets is parallel to the rolling direction of plate. Its mechanical properties of longitudinal direction are Tensile strength of $456.11 \mathrm{MPa}$, Yield stress of $370 \mathrm{MPa}$, Elongation of $21.7 \%$ and Young's modulus of $73.29 \mathrm{GPa}$.

Thin sheets with different thicknesses were LPF by a YAG laser system with $1064 \mathrm{~nm}$ wavelength and overlapping square spots of $4 \mathrm{~mm} \times 4 \mathrm{~mm}$, as shown in Fig. 2. Free stated thin sheets without and with heel block were LPF with $40 \mathrm{~mm}$ shocked area in length direction. The LPF area is symmetrical to the center line in the length direction. Both scanning velocity $\mathrm{V}_{\mathrm{y}}$ at the length direction and step interval $\mathrm{Vx}$ at the width direction are $3.4 \mathrm{~mm}$. Laser process parameters are laser energy of $15 \mathrm{~J} /$ pulse, $20 \mathrm{~J} /$ pulse, $25 \mathrm{~J} /$ pulse and $30 \mathrm{~J} /$ pulse. Pulse width is $15 \mathrm{~ns}$ in Full Width at Half Maximum (FWHM). Repetition frequency is $1 \mathrm{~Hz}$. The square spots were focused at the surface of thin sheets by a beam shaping device with a lens and a shaping lens. A water curtain of about $1 \mathrm{~mm} \sim 2 \mathrm{~mm}$ thickness was used as a confined layer. An aluminum foil of about $0.12 \mathrm{~mm}$ thickness was served as an absorbed layer.

Arc heights of thin sheets with LPF were measured by arc height tester with TSL-3A and a 31.75 $\mathrm{mm} \times 15.87 \mathrm{~mm}$ measured area. Bending deformation profiles of thin sheets along the length direction were measured by dial indicator and its support frame based on an optical platform and achieved around the $\mathrm{Y}$-axis into the Z-direction. The optical platform was adjusted by electronic water balance meter adjustment (shaft level $300 \mathrm{~mm}, 1 \mathrm{DIV}=0.02 \mathrm{~mm} / \mathrm{m}$ ). The measurement path of bending deformation profiles was at the center line of the width direction, as shown in Fig. 2.

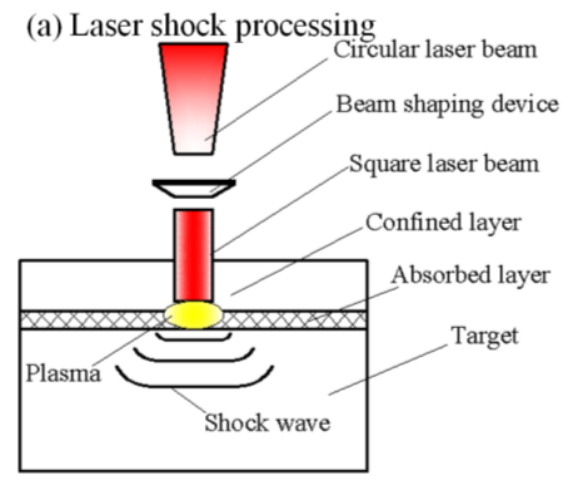

(b) Laser peen forming

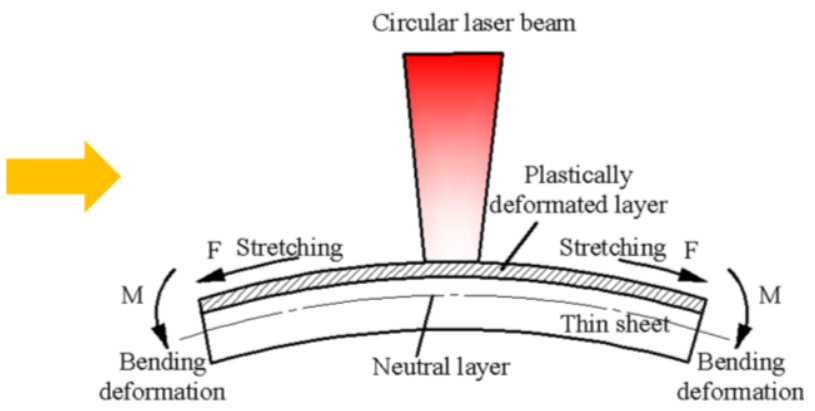


Figure 1. Schematic diagram of LPF process, (a) LSP, (b) LPF.

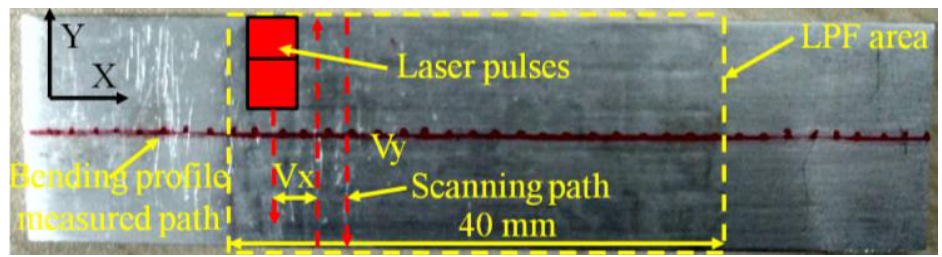

Figure 2. LPF area and bending profile measured path.

\section{Results and discussions}

\subsection{Surface morphology of aluminum foil}

Fig. 3 shows surface morphology of aluminum foil of thin sheets with different process parameters. It presents that bulge on the aluminum foil is generated at the bottom surface of thin sheets and bulge height increases with the decreasement of thin sheet thickness, as shown in Fig. 3(a) Fig. 3(c). However, no bulge on the aluminum foil is generated at the bottom surface of thin sheets with heel block, as shown in Fig. 3(d). The reason may be ascribed to shock wave propagation into the heel block or bulge on the aluminum foil restricted by heel block [12]. In addition, it can be seen clearly that no bulge on the aluminum foil is generated at the topmost surface of thin sheets with different thicknesses, which indicates that no or little reflection wave and no negative effect are formed inside the thin sheet. The reason may be attributed to aluminum foil used for absorbed wave layer, which can absorb the laser shock wave and avoid the reflected wave to propagate into the thin sheet. Therefore, aluminum foil at the bottom surface should be used for thin sheets with LPF, which can effective avoid the negative effect and improve the mechanical property of thin sheets.
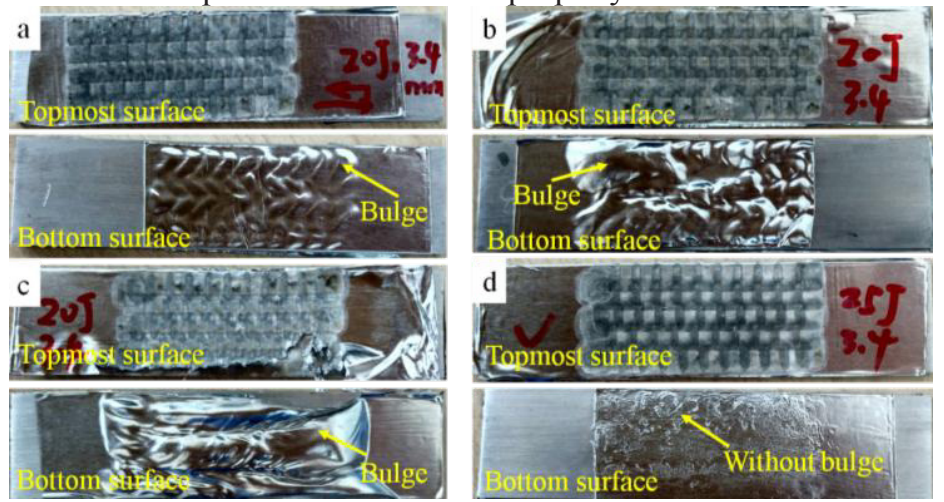

Figure 3. Surface morphology of aluminum foil of thin sheets with different process parameters, (a) $3 \mathrm{~mm}$ thickness sheet and $20 \mathrm{~J}$ laser energy and without heel block, (b) $2 \mathrm{~mm}$ thickness sheet and $20 \mathrm{~J}$ laser energy and without heel block, (c) $1 \mathrm{~mm}$ thickness sheet and $20 \mathrm{~J}$ laser energy and without heel block, (d) $1 \mathrm{~mm}$ thickness sheet and $25 \mathrm{~J}$ laser energy and with heel block.

\subsection{Different constraint conditions}

Fig. 4 shows arc heights of $1 \mathrm{~mm}$ thickness sheets with LPF under different constraint conditions. It can be seen from Fig. 4(a) that the arc heights at the topmost surface of thin sheets are $0.075 \mathrm{~mm}$ for $15 \mathrm{~J}$ with heel block, $-0.816 \mathrm{~mm}$ for $20 \mathrm{~J}$ without heel block, $-0.064 \mathrm{~mm}$ for $25 \mathrm{~J}$ with heel block, respectively. It indicates that more large plastic deformation is generated on thin sheet without heel block compared to that of thin sheet with heel block. The reason may be attributed to plastic 
deformation along the depth of thin sheets is not restricted under the condition without heel block. In addition, $1 \mathrm{~mm}$ thickness thin sheets produce two-way bending deformations with convex deformation of positive value and concave deformation of negative value, as shown in Fig. 4(b). About $25 \mathrm{~J}$ is the transition value of two-way bending deformations of $1 \mathrm{~mm}$ thickness sheets under the condition of heel block. And transition value of two-way bending deformations of $1 \mathrm{~mm}$ thickness sheets is less than $20 \mathrm{~J}$ under the condition without heel block.
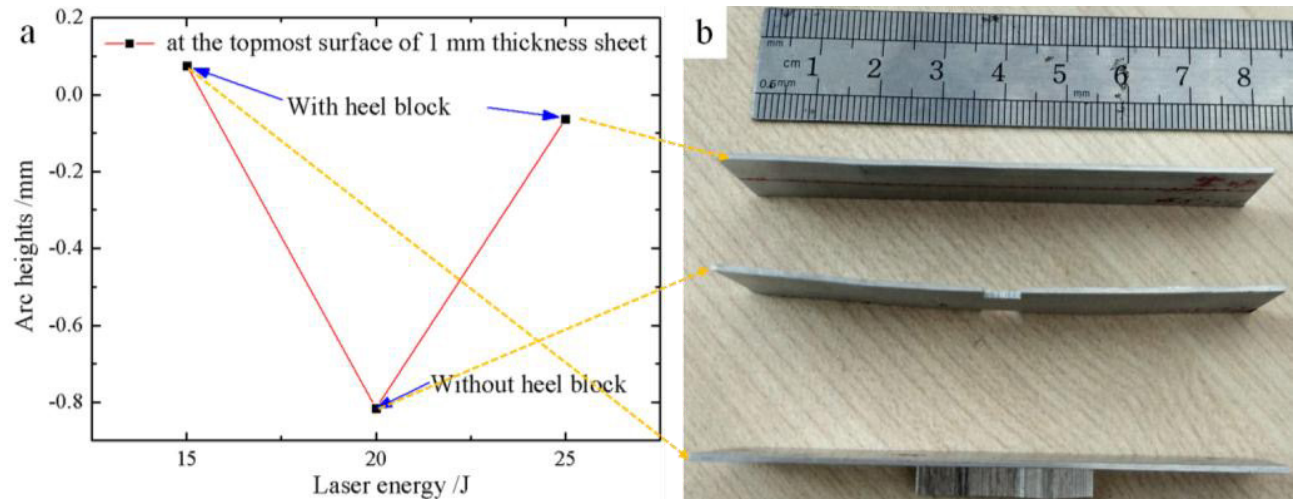

Figure 4. The arc heights of $1 \mathrm{~mm}$ thickness sheets with LPF under different constraint conditions, (a) arc heights value, (b) photos of deformed out of sheets.

\subsection{Different sheet thicknesses}

Fig. 5 shows arc heights of thin sheets with different thicknesses after LPF without heel block. It can be seen clearly in Fig. 5(a) that arc heights at the topmost surface of thin sheets after LPF with laser energy of $20 \mathrm{~J}$ are $-0.816 \mathrm{~mm}$ for $1 \mathrm{~mm}$ thickness, $0.138 \mathrm{~mm}$ for $2 \mathrm{~mm}$ thickness and $0.206 \mathrm{~mm}$ for 3 $\mathrm{mm}$ thickness, respectively. It indicates that remain flat thickness of thin sheets after LPF with laser energy of $20 \mathrm{~J}$ is about $1 \mathrm{~mm} \sim 2 \mathrm{~mm}$. The reason may be ascribed to the increasement of ratio of compressive residual stress layer/ sheet thickness. Fig. 5 presents that arc heights of $2 \mathrm{~mm}$ thickness sheets are less than those of $3 \mathrm{~mm}$ thickness sheets after LPF with $20 \mathrm{~J}, 25 \mathrm{~J}$ and $30 \mathrm{~J}$. The reason may be ascribed to compressive residual stress layer reaching the bottom surface of thin sheets. Arc heights at the topmost surface of thin sheets are $0.13 \mathrm{~mm}$ for $2 \mathrm{~mm}$ thickness sheet and $0.221 \mathrm{~mm}$ for $3 \mathrm{~mm}$ thickness after LPF with laser energy of $25 \mathrm{~J}$. They are $0.136 \mathrm{~mm}$ for $2 \mathrm{~mm}$ thickness sheet and 0.239 $\mathrm{mm}$ for $3 \mathrm{~mm}$ thickness sheet after LPF with laser energy of $30 \mathrm{~J}$. Based on the above experimental data, remain flat thicknesses of thin sheets are about $1 \mathrm{~mm} \sim 2 \mathrm{~mm}$ for $20 \mathrm{~J}, 25 \mathrm{~J}$ and $30 \mathrm{~J}$.
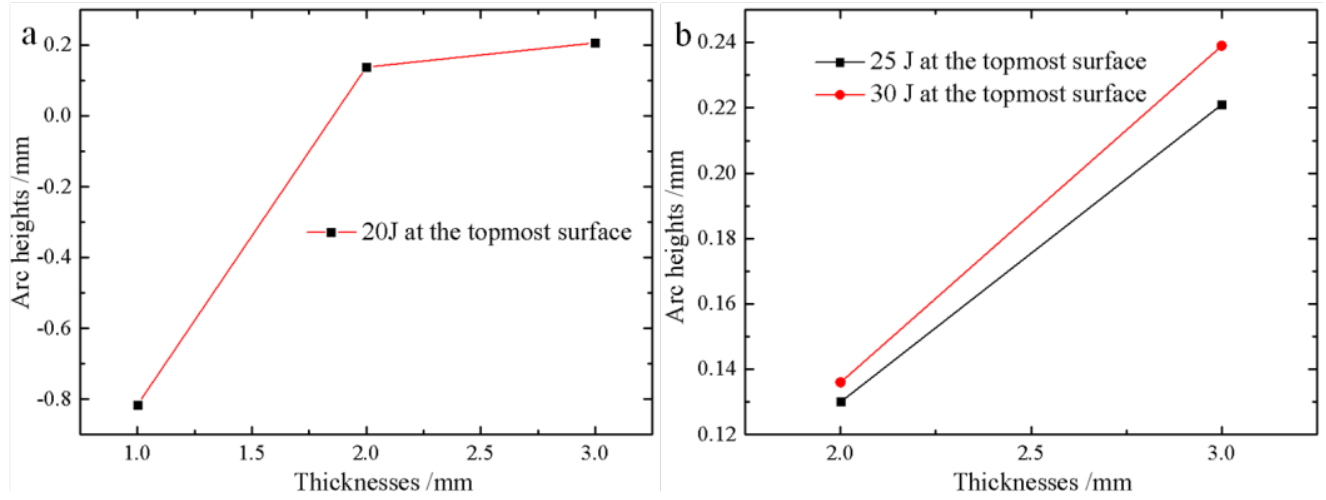

Figure 5. Arc heights of thin sheets with different thicknesses after LPF without heel block, (a) 20J, (b) 25J and $30 \mathrm{~J}$. 


\subsection{Different laser energies}

Fig. 6 shows bending deformations of thin sheets after LPF with different laser energies. Bending deformations of $3 \mathrm{~mm}$ thickness sheets gradually increase with the increasement of laser energy, which may be attributed to high amplitude and deep compressive residual stress layer induced by LPF. Arc heights $(h a)$ of $3 \mathrm{~mm}$ thickness sheets are $0.25 \mathrm{~mm}$ for $20 \mathrm{~J}, 0.29 \mathrm{~mm}$ for $25 \mathrm{~J}$ and $0.31 \mathrm{~mm}$ for 30 $\mathrm{J}$ in shocked area with chord length $(L c)$ of constant $40 \mathrm{~mm}$, as shown in Fig. 6(a). According to the calculated formula of curvature radius [13], curvature radii $(R)$ of $3 \mathrm{~mm}$ thickness sheets are about 800 $\mathrm{mm}$ for $20 \mathrm{~J}, 690 \mathrm{~mm}$ for $25 \mathrm{~J}$ and $645 \mathrm{~mm}$ for $30 \mathrm{~J}$, respectively. Fig. 6(b) shows arc heights of $2 \mathrm{~mm}$ thickness sheets after LPF with different laser energies in arc height tester with chord length $(L c)$ of $31.75 \mathrm{~mm}$. It indicates that arc heights of $2 \mathrm{~mm}$ thickness sheets make little change with the increasement of laser energy, which may be ascribed to compressive residual stress reaching to the bottom surface.Arc heights for $2 \mathrm{~mm}$ thickness sheets at the topmost surface are $0.138 \mathrm{~mm}$ for $20 \mathrm{~J}$, $0.13 \mathrm{~mm}$ for $25 \mathrm{~J}$ and $0.136 \mathrm{~mm}$ for $30 \mathrm{~J}$, respectively.
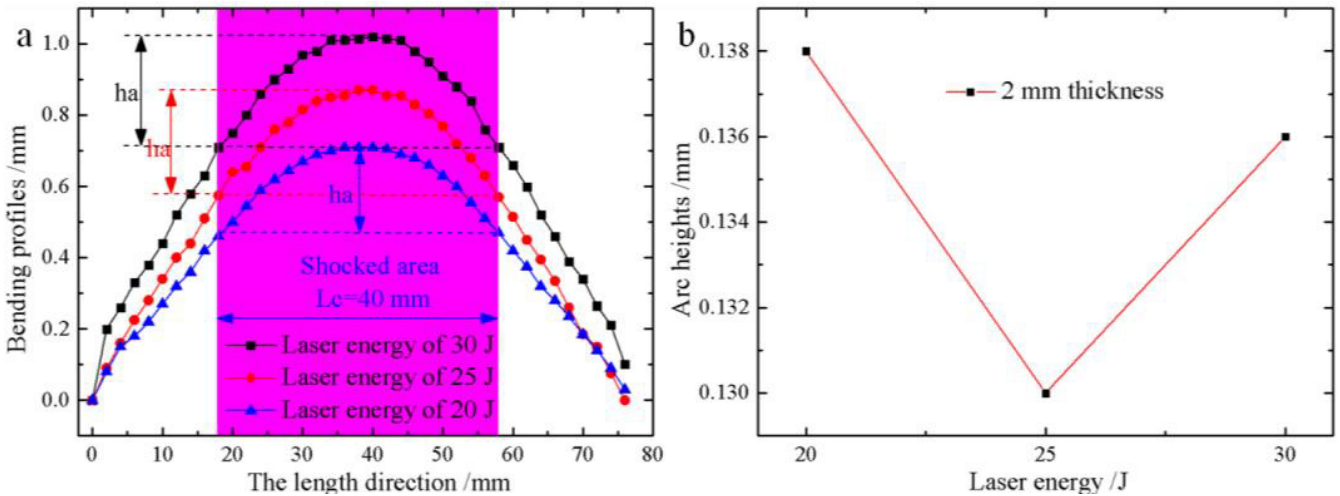

Figure 6. Bending deformations of thin sheets after LPF with different laser energies, (a) $3 \mathrm{~mm}$ thickness sheets, (b) $2 \mathrm{~mm}$ thickness sheets.

\subsection{Bending deformation types}

Bending deformation types of thin sheets with LPF are shown in Fig. 7. It can be seen that different bending deformation types induced by LPF are convex deformation, flat, concave deformation and laser deep drawing. The similar results have been reported [4,11]. When the depth of plastic deformation layer is small to sheet thickness, only elongation is generated in the surface layer. The curvature will emerge convex and increase to a maximum value. The convex curvature would decrease with the increasement of sheet thickness. Convex deformation of thin sheets will transform into concave deformation with the decreasement of sheet thickness. When compressive residual stress layer depth reach to the bottom surface, thin sheets keep flat. However, when sheet thickness is too thin or plasic deformation induced by LPF is not restricted by sheet, laser deep drawing is generated on thin sheets, as shown in Fig. 7. 


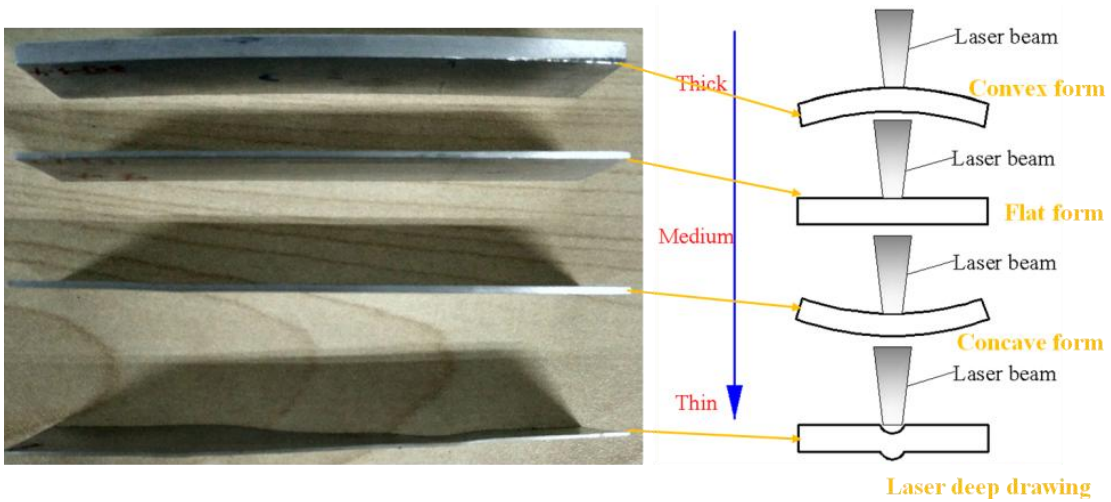

Figure 7. Bending deformation types of thin sheets with LPF.

\section{Summary}

LPF experiments have been performed to understand the effect of process parameters on the surface morphology and bending deformation of thin sheets with different thicknesses. The following conclusions have been reached:

(1) Bulges on the aluminum foil are generated at the bottom surface of 2024-T3 thin sheets with LPF and bulges heights increase with the decreasement of sheet thickness. No bulges on the aluminum foil at the topmost surface are generated. More large plastic deformation is generated on thin sheet without heel block compared to that of thin sheet with heel block.

(2) The arc heights at the topmost surface of thin sheets are $0.075 \mathrm{~mm}$ for $15 \mathrm{~J}$ with heel block, $0.816 \mathrm{~mm}$ for $20 \mathrm{~J}$ without heel block, $-0.064 \mathrm{~mm}$ for $25 \mathrm{~J}$ with heel block, respectively. It is obtained by transition values of two-way bending deformations on thin sheets with LPF. They are about $25 \mathrm{~J}$ and less than $20 \mathrm{~J}$ for $1 \mathrm{~mm}$ thickness sheets with heel block and without heel block, respectively. Remain flat thicknesses of thin sheets are about $1 \mathrm{~mm} \sim 2 \mathrm{~mm}$ for $20 \mathrm{~J}, 25 \mathrm{~J}$ and $30 \mathrm{~J}$.

(3) Arc heights $(h a)$ of $3 \mathrm{~mm}$ thickness sheets with LPF gradually increase with laser energy of $20 \mathrm{~J} \sim 30 \mathrm{~J}$. Curvature radii $(R)$ of $3 \mathrm{~mm}$ thickness sheets with LPF become small with laser energy of $20 \mathrm{~J} \sim 30 \mathrm{~J}$. However, arc heights of $2 \mathrm{~mm}$ thickness sheets with LPF make little change with laser energy of $20 \mathrm{~J} \sim 30 \mathrm{~J}$. Different bending deformation types after LPF are convex deformation, flat, concave deformation and laser deep drawing with the decreasement of sheet thicknesses.

\section{References}

1. C. B. Dane, L. Hackel, F. Harris, D. Francis, Recent progress in laser technology for industrial laser peening, 4th International Conference on Laser Peening, Madrid, Spain 2013.

2. A. Telang, A. S. Gill, S. Teysseyre, S.R. Mannava, D. Qian, V. K. Vasudevan, Effects of laser shock peening on SCC behavior of Alloy 600 in tetrathionate solution, Corros. Sci. 90 (2015) 434-44.

3. C. Correa, L. R. D. Lara, M. Díaz, J. A. Porro, A. García-Beltrán, J. L. Ocaña, Influence of pulse sequence and edge material effect on fatigue life of Al2024-T351 specimens treated by laser shock processing, Int. J. Fatigue 70 (2015) 196-204.

4. Y. X. Hu, X. X. Xu, Z. G. Yao, J. Hu, Laser peen forming induced two way bending of thin sheet metals and its mechanisms, J. Appl. Phys. 108 (2010) 235-359.

5. J. L. Ocana, M. Morales, J. J. Garcia-Ballesteros, J. A. Porro, O. Garcia, C. Molpeceres, Laser shock microforming of thin metal sheets, Appl. Surf. Sci. 255 (2009) 5633-5636.

6. Y. Sagisaka, K. Yamashita, W. Yanagihara, H. Ueta, Microparts processing using laser cutting and ultra-short-pulse laser peen forming, J. Mater. Process. Technol. 219 (2015) 230-236. 
7. Y. Sagisaka, M. Kamiya, M. Matsuda, Y. Ohta, Thin-sheet-metal bending by laser peen forming with femtosecond laser, J. Mater. Process. Technol. 210 (2010) 2304-2309.

8. Y. X. Hu, M. S. Luo, Z. Q. Yao, Increasing the capability of laser peen forming to bend titanium alloy sheets with laser-assisted local heating, Mater. Des. 90 (2016) 364-372.

9. Y. X. Hu, Z. Li, X. C. Yu, Z. Q. Yao, Effect of elastic prestress on the laser peen forming of aluminum alloy 2024-T351: Experiments and eigenstrain-based modeling, J. Mater. Process. Technol. 221 (2015) 214-224.

10. N. G. Shen, H. T. Ding, Q. H. Wang, H. Ding, Effect of confinement on surface modification for laser peen forming without protective coating, Surf. Coat. Technol. 289 (2016) 194-205.

11. Y. Sagisaka, Application of Femtosecond Laser Peen Forming to Sheet Metal Bending, J. Laser Micro/nanoeng. 7 (2012) 158-163.

12. Z. G. Che, S. L. Gong, Z. W. Cao, S. K. Zou, Y. Gao, H. Ma, Theory Analysis and Experiment Investigation of Laser Shock Processing on Titanium Alloy Blade, Rare Metal Mat. Eng. 40 (2011) 235-239.

13. A. Gariépy, S. Larose, C. Perron, P. Bocher, M. Lévesque, On the effect of the orientation of sheet rolling direction in shot peen forming, J. Mater. Process. Technol. 213 (2013) 926-938. 